\title{
Ordered Intermetallic Nanostructured PtSb/C for Production of Energy and Chemicals
}

\author{
T. P. Scachetti ${ }^{1}$ - A. C. D. Angelo ${ }^{1}$
}

Published online: 28 July 2015

(C) Springer Science+Business Media New York 2015

\begin{abstract}
This paper has evaluated ordered intermetallic nanostructured $\mathrm{PtSb} / \mathrm{C}$ as anode for glycerol electrochemical oxidation in both acidic and alkaline media. Nanostructured $\mathrm{PtSb} / \mathrm{C}$ performed as well as and $50 \%$ better than commercially available $\mathrm{Pt} / \mathrm{C}$ nanoparticles in acidic and basic media, respectively. The presence of $\mathrm{Sb}$ atoms in the material structure enhanced $\mathrm{C}-\mathrm{C}$ bond cleavage activation in alkaline medium. Spectroelectrochemical studies confirmed that the reactions conducted in acidic and alkaline solutions produced high-value chemicals. Depending on the nature of the employed electrolyte, the nanostructured $\mathrm{PtSb} / \mathrm{C}$ material can potentially afford interesting compounds for the chemical industry or even generate electrical energy.
\end{abstract}

Keywords Ordered intermetallic $\cdot$ Glycerol $\cdot$ PtSb . Electrooxidation $\cdot$ Nanostructure

\section{Introduction}

Glycerol can assume a remarkable strategic role in sustainable development. It easily originates from the transesterification of fats, oils, and other renewable sources; it is also a byproduct of biodiesel production. Unfortunately, glycerol constitutes a potential environmental pollutant if discharged improperly. Because biodiesel production has made glycerol in-

\section{A. C. D. Angelo}

acangelo@fc.unesp.br

1 Electrocatalysis Laboratory, Chemistry Department, UNESP, Bauru, Sao Paulo, Brazil creasingly available, the search for alternative applications of this polyol has become an urgent matter.

Glycerol can serve as fuel in direct alcohol fuel cells - this polyol can potentially transfer 14 electrons per molecule. It is also a unique source of chemicals for several important industrial sectors. Studies on glycerol electrochemical oxidation have focused on the use of noble metals as electrocatalysts [1-11]. The use of binary or ternary intermetallic materials can further enhance alcohol electrooxidation as a result of (1) bifunctional action, (2) variation in the electronic state of the adsorption site, (3) third-body effect, or (4) a combination of such effects.

As a rule, researchers have pursued C-C cleavage, which seems to be the main hindrance to enhancing the electrooxidation of alcohols bearing long carbon chains. Authors have also sought to inhibit the poisoning effect that some intermediates/products exert on the electrooxidation pathway. In the particular case of glycerol electrooxidation, C-C bond cleavage could improve the reaction enormously: it could favor the transfer of a larger number of electrons from the same molecule. In this context, Simões et al. studied glycerol electrooxidation on Pd-based catalysts containing $\mathrm{Au}$ and $\mathrm{Ni}$, in alkaline medium [2]. The Pd-based anodes performed just as well as Pt, but the PdNi material stood out for its good performance and low cost. The reaction mechanism depended on catalyst composition. Kim et al. investigated glycerol oxidation at a PtRuSn anode in acidic medium [12]. The anode performance resulted from electronic and geometric effects; the trimetallic system avoided the poisoning action of reaction intermediates. Falase et al. compared how PtRu, PtSn, and PtRuSn alloys behaved as anode for glycerol electrooxidation in alkaline medium [13]. $\mathrm{Pt}_{84} \mathrm{Sn}_{16}$ performed the best among the assessed materials. More recently, Zalinneva et al. evaluated glycerol oxidation on the surface of PdBi alloys [14]. $\mathrm{Pd}_{4} \mathrm{Bi}$ was the best anode as a consequence of its electronic 
effect. Products originating from different mechanisms arose during the reaction, e.g., carboxylates, ketones, and aldehydes.

Ordered intermetallic phases have become a very interesting tool for electrocatalytic studies - these materials combine high physicochemical stability with ordered surface, which allows investigation into how electrode performance depends on the electrode characteristics. In addition, the synthesis of these phases as nanoparticles enables their application in real systems. Few studies have used ordered intermetallic phases as active material in electrochemical reactions, even though this type of nanoparticles presents promising performance [15-21]. In particular, ordered intermetallic PtSb constitutes a potential electrocatalyst for alcohol electrooxidation [17]. Nonetheless, the literature does not bring any studies on the performance of this electrode material in glycerol oxidation.

The present paper reports on the outstanding performance of the ordered intermetallic nanoparticle $\mathrm{PtSb} / \mathrm{C}$ as anode for glycerol electrooxidation in both acidic and alkaline media. Compared with $\mathrm{Pt} / \mathrm{C}$, the $\mathrm{PtSb} / \mathrm{C}$ material reported herein enhances the electrode reaction kinetics and generates industrially important chemicals.

\section{Experimental}

Ordered intermetallic PtSb nanoparticles supported on carbon (Vulcan XC-72, Cabot) were synthesized via the polyol route proposed by Schaak [22]. To this end, proper amounts of $\mathrm{H}_{2} \mathrm{Cl}_{6} \mathrm{Pt} \cdot 6 \mathrm{H}_{2} \mathrm{O}$ (Merck, p.a.) and $\mathrm{SbCl}_{3}$ (Sigma-Aldrich, p.a.) were dissolved in tetraethylene glycol (TEG) in the presence of carbon previously treated in argon atmosphere at $400{ }^{\circ} \mathrm{C}$ for 4 h. Polyvinylpyrrolidone (PVP, Sigma-Aldrich, p.a.) served as dispersing agent and stabilizer. Sodium borohydride $\left(\mathrm{NaBH}_{4}\right.$, Sigma-Aldrich, $\left.98 \%\right)$ was employed as an auxiliary reducing agent. Further details of the synthesis are available in our previous paper [17]. The performance of the synthesized material was compared with the performance of commercially available $\mathrm{Pt} / \mathrm{C}$ (E-TEK). X-ray diffraction revealed that the product consisted of ordered intermetallic PtSb. A powder method setup was used in the X-ray Diffractometer Rigaku Ultima IV; a $\mathrm{Cu}$ anode operating at $40 \mathrm{kV}$ and $20 \mathrm{~mA}$ was the $\mathrm{X}$-ray source $(\mathrm{Cu} \mathrm{K} \alpha, \lambda=1.5406 \AA)$. The diffractograms were recorded for $2 \theta$ values ranging from 10 to 100 , at a scan rate of $1 \% \mathrm{~min}$. The material was also examined under a ZEISS LEO 440 scanning electron microscope (SEM) coupled to an energy dispersive X-ray analyzer (EDX Link Analytical). Co served as calibrator; the operating parameters were as follows: electron beam energy $=20 \mathrm{kV}$, focal distance $=25 \mathrm{~mm}$, dead time $=30 \%$, current $=2.82 \mathrm{~A}$, and I probe $=950 \mathrm{pA}$. To estimate the relative amount of metals in the sample, five points were randomly selected on the surface. To enable visualization of individual or agglomerated particles, the sample was observed under a transmission electron microscope (JEOL JEM 2100) operating at $200 \mathrm{~kW}$. The materials were deposited on a polished glassy carbon surface as a thin film obtained from a dispersion consisting of the supported nanoparticles, isopropyl alcohol, Nafion ${ }^{\circledR}$ (Nafion 117, Aldrich), and deionized water. The as-prepared surface was submitted to electrochemical and electrochemical/spectroscopic studies. For the electrochemical studies (cyclic voltammetry and chronoamperometry), $\mathrm{HClO}_{4}$ (Merck, 70-72\%) or $\mathrm{NaOH}$ (Merck, p.a.) was used as a $0.15 \mathrm{~mol} \mathrm{~L}^{-1}$ solution at $25 \pm$ $1{ }^{\circ} \mathrm{C}$; a large surface $\mathrm{Pt}$ wire and reversible hydrogen electrode (RHE) worked as the counter-electrode and reference electrode, respectively. Infrared reflectance spectroscopy (IRRS) was conducted on the Nicolet Model 670 Spectrophotometer with MCT detector, coupled to a Wenking POS 73 Potentiostat and a function generator Prodis 1/161. $\mathrm{A} \mathrm{CaF}_{2}$ window was used to detect adsorbed intermediates. The experiments were set up through the OMNIC E.S.P.5.2 software. Further details on the spectrophotometric studies are available elsewhere [4].

\section{Results and Discussion}

\section{Characterization}

Figure 1 displays the X-ray diffractogram of $\mathrm{PtSb} / \mathrm{C}$. Compared with PDF \#AL5068 for ordered intermetallic PtSb and PDF \#8050 for $\mathrm{Sb}_{2} \mathrm{O}_{5}$, the synthesized material unequivocally consists of ordered intermetallic $\mathrm{PtSb} / \mathrm{C}$ containing a negligible amount of $\mathrm{Sb}_{2} \mathrm{O}_{5}$ as a second phase. Because the obtained pattern agrees well with the PDF from the Crystmet Database [23], we concluded that the material pertains to the hexagonal system, $\mathrm{P} 6_{3} / \mathrm{mmc}$, with crystallographic parameters $a$ and $c$ of 4.14 and $5.44 \AA$, respectively, and cell volume of $84.44 \AA^{3}$.

The EDX assay revealed that the composition of the produced material is $\mathrm{Pt}=55.4 \pm 1.0$ and $\mathrm{Sb}=44.6 \pm 1.0$ atom\%, which is very close to the 50 atom $\%$ nominal composition. The slight difference between the amounts of $\mathrm{Pt}$ and $\mathrm{Sb}$ in the material stems from the segregation mentioned earlier in the paragraph on X-ray characterization.

Figure 2 shows a representative TEM micrograph and the corresponding histogram built from sample analysis. The particles resemble spheroids; they agglomerate in undesirable clusters. Size distribution demonstrates that most particles measure $2 \mathrm{~nm}$.

\section{Electrochemical Characterization and Evaluation}

Figure 3 depicts the cyclic voltammograms of the $\mathrm{PtSb} / \mathrm{C}$ and $\mathrm{Pt} /$ $\mathrm{C}$ surfaces in $\mathrm{HClO}_{4}$ and $\mathrm{NaOH}$ electrolyte solutions. The registered profiles correspond to the last profile of a series of 20 voltammetric cycles. The profiles are reproducible. No variations 
Fig. 1 X-ray diffraction (XRD) of ordered intermetallic PtSb nanoparticles supported on Vulcan XC-72 carbon black

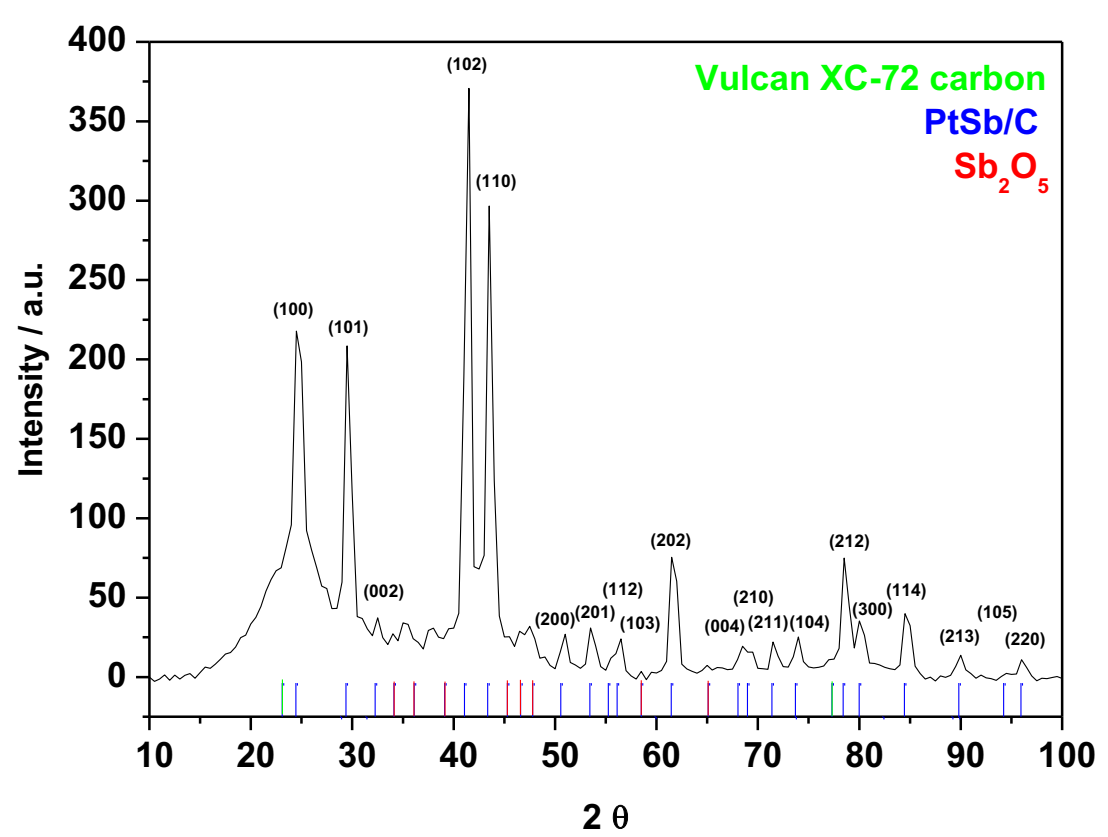

that could point to surface modification or leaching of the electrode elements are evident along cycling. In general, surface processes are more poorly defined in acidic medium than in alkaline medium. Nevertheless, Fig. 3 evidences the regions referring to hydrogen processes (hydrogen desorption and adsorption, region I), the double layer (region II), and surface oxidation (region III). The capacitive current densities involved in region II are approximately the same for all the materials and media, which suggests that the exposed surface area is similar in all cases. This feature should facilitate comparison of the materials as anodes for glycerol electrooxidation. Compared with alkaline medium, less positive potentials are necessary for oxides to arise on the $\mathrm{PtSb} / \mathrm{C}$ surface in acidic solution. Under the same experimental conditions, oxides originate on the $\mathrm{PtSb} / \mathrm{C}$ surface at less positive potentials as compared with Pt. Together, these observations indicate that the oxophilic action of surface $\mathrm{Sb}$ atoms is probably more effective in acidic medium.

Figure 4 illustrates representative chronoamperometric curves obtained for glycerol oxidation on $\mathrm{Pt} / \mathrm{C}$ and $\mathrm{PtSb} / \mathrm{C}$ surfaces in both $\mathrm{HClO}_{4}$ and $\mathrm{NaOH}$ electrolytes. At $0.6 \mathrm{~V}$, in acidic medium, the current initially drops and then increases along time for both $\mathrm{Pt} / \mathrm{C}$ and $\mathrm{PtSb} / \mathrm{C}$. This transient decay is
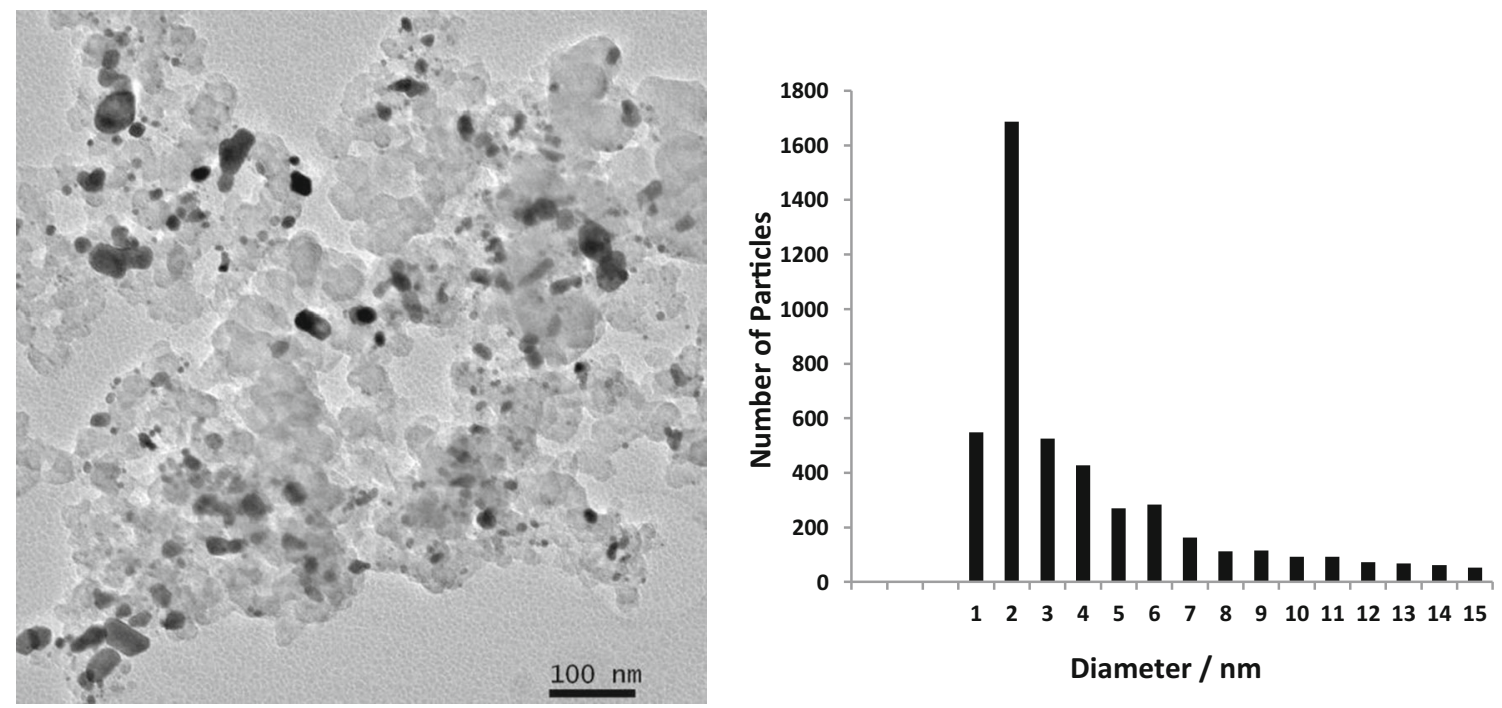

Fig. 2 TEM micrograph and histogram of the particle diameter distribution of ordered intermetallic PtSb/C nanoparticles 
Fig. 3 Cyclic voltammograms of $\mathrm{Pt} / \mathrm{C}$ in $\mathbf{a ~} \mathrm{HClO}_{4} 0.15 \mathrm{~mol} \mathrm{~L}^{-1}$ and b $\mathrm{NaOH} 0.15 \mathrm{~mol} \mathrm{~L}^{-1}$ and of $\mathrm{PtSb} / \mathrm{C}$ in $\mathbf{c} \mathrm{HClO}_{4} 0.15 \mathrm{~mol} \mathrm{~L}^{-1}$ and $\mathbf{d ~ N a O H ~} 0.15 \mathrm{~mol} \mathrm{~L}^{-1} . T=$ $25^{\circ} \mathrm{C} ; v=20 \mathrm{mV} \mathrm{s}^{-1}$
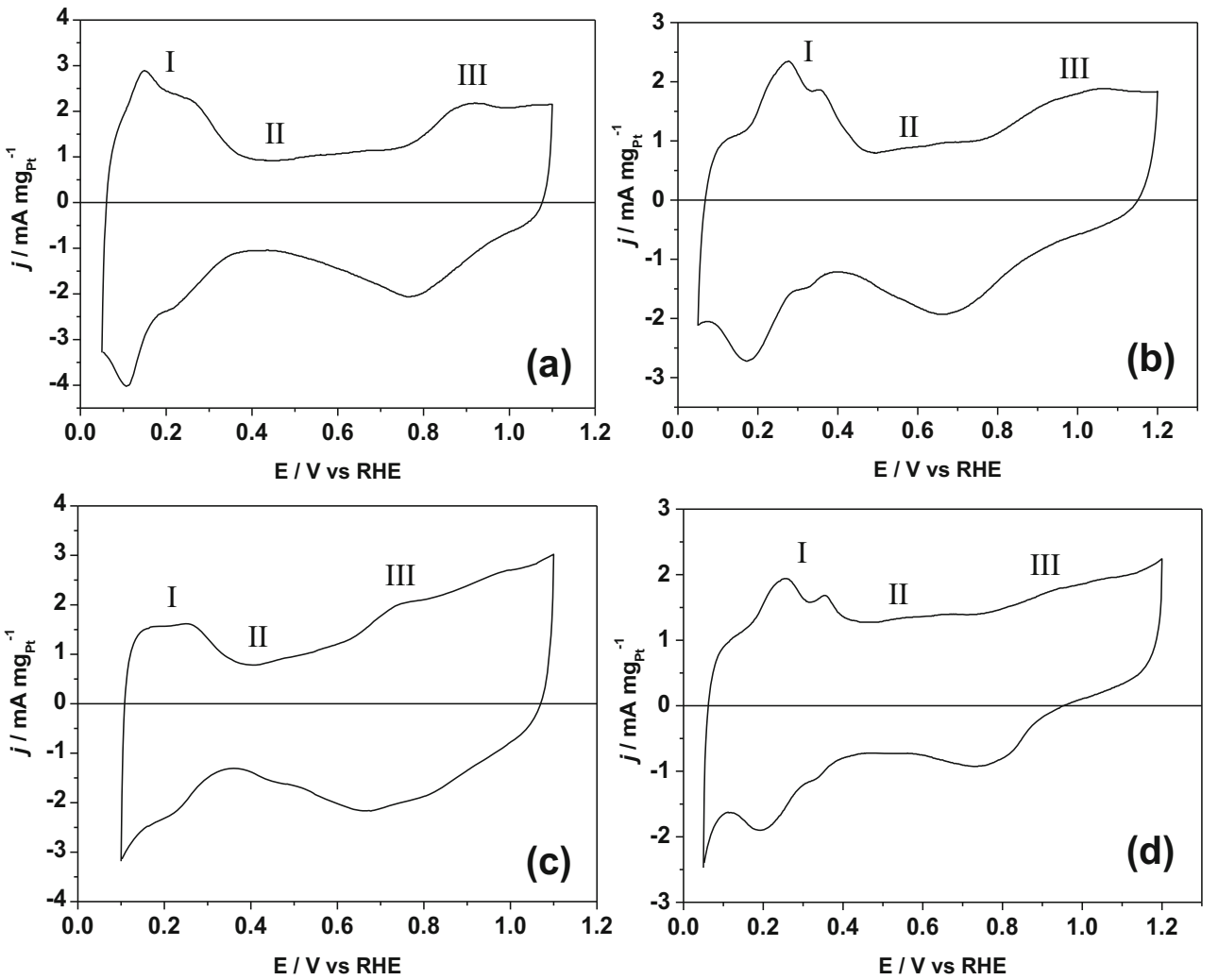

more pronounced for $\mathrm{Pt} / \mathrm{C}$ than for $\mathrm{PtSb} / \mathrm{C}$, even though the current stabilizes within a shorter period in the former case. This reduction in current probably results from the doublelayer capacitive discharge; however, it could not be discarded a contribution of oxidized species formation on the material surface, which in turn enhances glycerol oxidation. The reduction is more noticeable for $\mathrm{Pt} / \mathrm{C}$, because oxidation of this material requires more energy than $\mathrm{PtSb} / \mathrm{C}$ oxidation, as earlier mentioned in this section. Indeed, $\mathrm{Sb}$ atoms are oxophilic, which should favor oxide formation on the $\mathrm{PtSb} / \mathrm{C}$ surface. Moreover, the curve for $\mathrm{Pt} / \mathrm{C}$ stabilizes at a higher current density $\left(j_{0.6 \mathrm{~V}}=0.9 \mathrm{~mA} \mathrm{mg}_{\mathrm{Pt}}{ }^{-1}\right)$ as compared with $\mathrm{PtSb} / \mathrm{C}\left(j_{0.6 \mathrm{~V}}=0.6 \mathrm{~mA} \mathrm{mg}{ }_{\mathrm{Pt}}{ }^{-1}\right)$, which experiences continuous decay along time. On the basis of these remarks, adsorbed species most likely accumulate on the $\mathrm{PtSb} / \mathrm{C}$ surface, and it is difficult to remove them along time. On the other hand, in
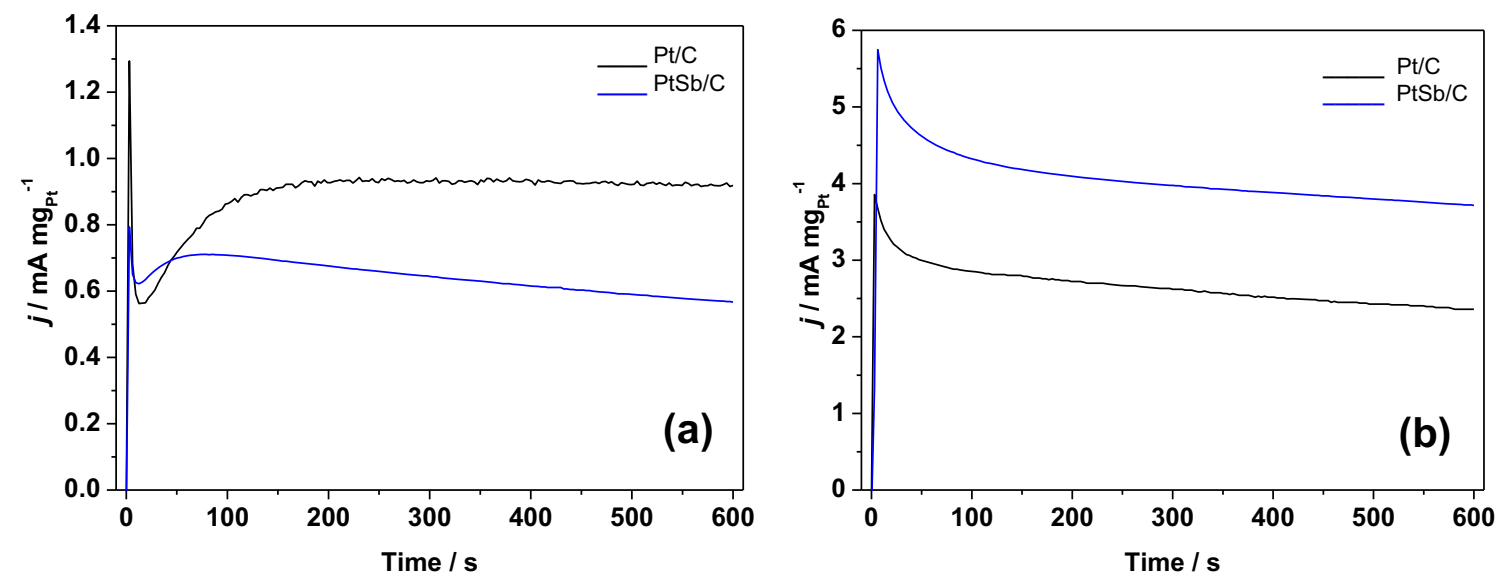

Fig. 4 Chronoamperometric curves for $\mathrm{Pt} / \mathrm{C}$ and $\mathrm{PtSb} / \mathrm{C}$ anodes in a $\mathrm{HClO}_{4} 0.15 \mathrm{~mol} \mathrm{~L}^{-1}$ and glycerol $0.15 \mathrm{~mol} \mathrm{~L}^{-1}$ and $\mathbf{b ~ N a O H ~} 0.15 \mathrm{~mol} \mathrm{~L}-1+$ glycerol $0.15 \mathrm{~mol} \mathrm{~L}^{-1} . T=25^{\circ} \mathrm{C}$ 
alkaline solutions, no initial transient current exists for any of the materials. Glycerol oxidation at the $\mathrm{PtSb} / \mathrm{C}$ anode reaches $46 \%$ higher current $\left(j_{0.6 \mathrm{~V}}=3.7 \mathrm{~mA} \mathrm{mg}_{\mathrm{Pt}}{ }^{-1}\right)$ as compared with $\mathrm{Pt} / \mathrm{C}\left(j_{0.6 \mathrm{~V}}=2.4 \mathrm{~mA} \mathrm{mg}_{\mathrm{Pt}}{ }^{-1}\right)$. The different anode behaviors verified in acidic and basic electrolytes could be associated with the availability of adsorbed $\mathrm{OH}^{-}$species on the electrode surface - in acidic solutions, these species originate from water molecule electrooxidation, whereas in alkaline solutions, the anode adsorbs $\mathrm{OH}^{-}$directly from the electrolyte $\left(\mathrm{HO}^{-}\right.$aq $)$.

Figure 5 brings the potentiodynamic and steady-state profiles of glycerol oxidation at $\mathrm{Pt} / \mathrm{C}$ and $\mathrm{PtSb} / \mathrm{C}$ anodes in acidic and alkaline solutions. Although the experimental conditions of the two techniques are clearly different, the steady-state curves fit the potentiodynamic curves quite well from a qualitative standpoint. The scan rate could slightly shift the potentiodynamic curves to more positive potentials. Figure 5a shows a pre-peak due to glycerol oxidation. Fernandez [24] reported that this pre-peak is due to $\mathrm{CO}_{2}$ formation from glycerol molecule adsorption and dissociation; however, in the present work, any $\mathrm{CO}_{2}$ production at potentials lower than $0.6 \mathrm{~V}$ was not detected.

Table 1 lists all the electrochemical parameters extracted from the electrochemical evaluation. Glycerol oxidation is faster in alkaline solution, probably because $\mathrm{OH}^{-}$species adsorb on the electrode surface and enhance the reaction mechanism. Peng et al. [25] proposed that, in alkaline medium, $\mathrm{Sb}$ atoms promote glycerol molecule adsorption in such a configuration that the $\mathrm{C}-\mathrm{H}$ bond has direct contact with Pt sites. This contact should inhibit oxygen adsorption and improve the kinetics of complete glycerol molecule oxidation. Moreover, these authors mentioned that the $\mathrm{Sb}$ atom electron-donor character leads to electronic density variation at the Pt adsorption sites. This should reduce the energy of intermediate adsorption onto $\mathrm{Pt}$, giving rise to vacant $\mathrm{Pt}$ sites. Another possible explanation for the superior performance of the $\mathrm{PtSb} / \mathrm{C}$ material is that $\mathrm{C}-\mathrm{C}$ bond cleavage prompts the transfer of a larger number of electrons. The discussion about the spectroelectrochemical studies will clarify this point.

\section{Electrochemical Infrared Reflectance Spectroscopy Studies}

Table 2 summarizes all the IRRS assignments and shows the literature sources on which attributions were based.
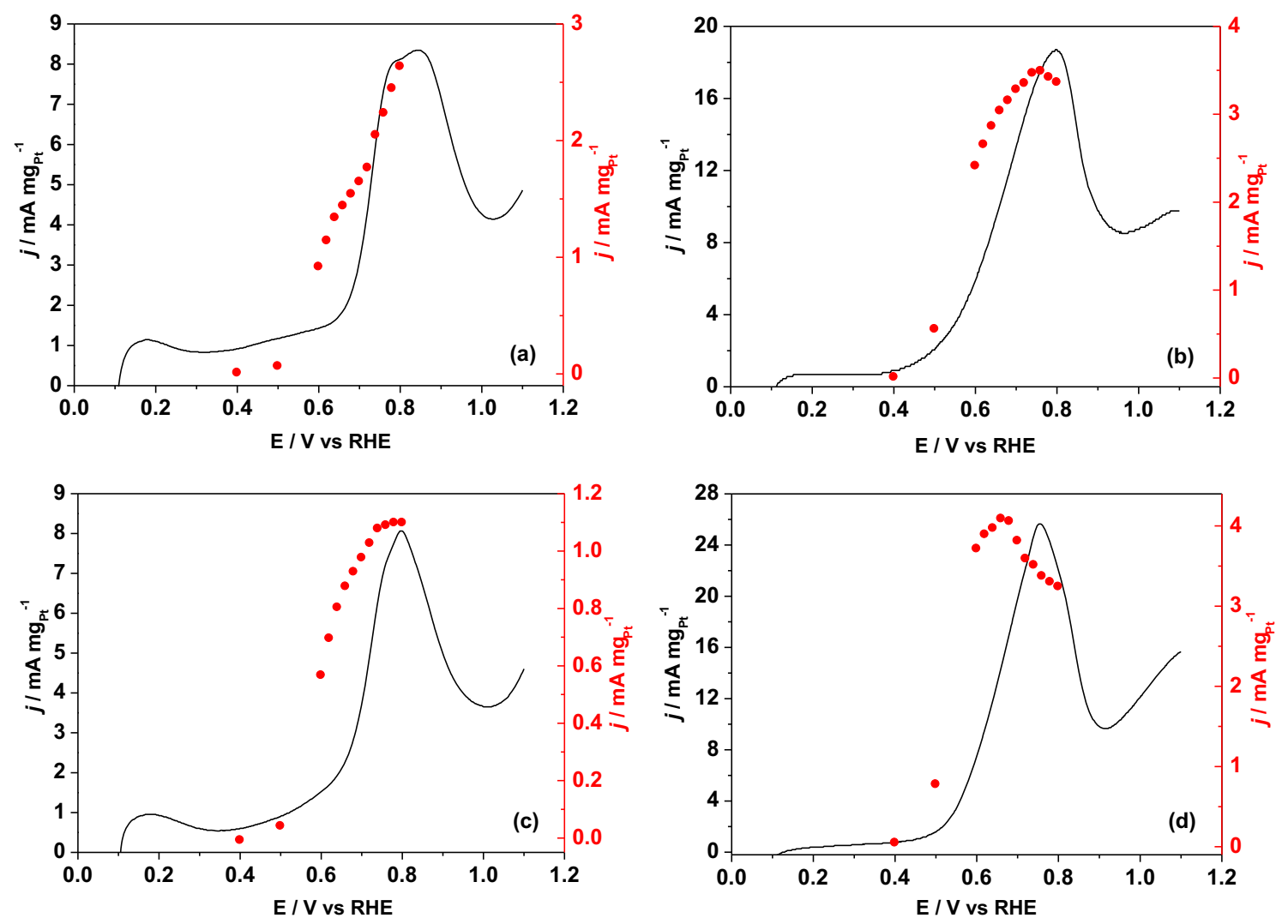

Fig. 5 Potentiodynamic curves (solid) and steady-state curves (doted) of $\mathrm{Pt} / \mathrm{C}$ in a $\mathrm{HClO}_{4} 0.15 \mathrm{~mol} \mathrm{~L}^{-1}+$ glycerol $0.15 \mathrm{~mol} \mathrm{~L}^{-1}$ and b $\mathrm{NaOH}$ $0.15 \mathrm{~mol} \mathrm{~L}^{-1}+$ glycerol $0.15 \mathrm{~mol} \mathrm{~L}^{-1}$ and of $\mathrm{PtSb} / \mathrm{C}$ in $\mathbf{c} \mathrm{HClO}_{4}$

$0.15 \mathrm{~mol} \mathrm{~L}^{-1}+$ glycerol $0.15 \mathrm{~mol} \mathrm{~L}^{-1}$ and $\mathbf{d ~ N a O H ~} 0.15 \mathrm{~mol} \mathrm{~L}^{-1}+$ glycerol $0.15 \mathrm{~mol} \mathrm{~L}^{-1} . T=25^{\circ} \mathrm{C} ; v=20 \mathrm{mV} \mathrm{s}^{-1}$ and $t=600 \mathrm{~s}$ 
Table 1 Electrochemical parameters extracted from the electrochemical evaluation (cyclic voltammetry) of glycerol electrooxidation at $\mathrm{PtSb} / \mathrm{C}$ and $\mathrm{Pt} / \mathrm{C}$ anodes in acidic and alkaline media

\begin{tabular}{|c|c|c|c|c|}
\hline & $\begin{array}{l}\text { Electrolyte } \\
{\left[0.15 \mathrm{~mol} \mathrm{~L}^{-1}\right]}\end{array}$ & $\begin{array}{l}\text { Onset } \\
\text { potential } \\
(\mathrm{V})\end{array}$ & $\begin{array}{l}\text { Peak current } \\
\text { density } \\
\left(\mathrm{mA} \mathrm{mg_{ \textrm {Pt } }}{ }^{-1}\right)\end{array}$ & $\begin{array}{l}\text { Oxidation peak } \\
\text { potential } \\
\text { (V) }\end{array}$ \\
\hline \multirow[t]{2}{*}{$\mathrm{Pt} / \mathrm{C}$} & $\mathrm{HCIO}_{4}$ & 0.50 & 8.30 & 0.85 \\
\hline & $\mathrm{NaOH}$ & 0.37 & 18.70 & 0.80 \\
\hline \multirow[t]{2}{*}{$\mathrm{PtSb} / \mathrm{C}$} & $\mathrm{HCIO}_{4}$ & 0.40 & 8.10 & 0.80 \\
\hline & $\mathrm{NaOH}$ & 0.40 & 25.60 & 0.75 \\
\hline
\end{tabular}

\section{Acidic Solution}

Figure 6 displays the electrochemical infrared reflectance spectroscopy (EIRRS) spectra obtained for glycerol electrooxidation at the $\mathrm{PtSb} / \mathrm{C}$ anode conducted in $\mathrm{HClO}_{4}$ solution. The set of peaks at 2943 and $2886 \mathrm{~cm}^{-1}$ corresponds to symmetric and asymmetric $\mathrm{CH}_{2}$ stretching related to glyceraldehyde consumed in the thin layer. The peak at $2342 \mathrm{~cm}^{-1}$ refers to $\mathrm{CO}_{2}$. No peak arose at $2040 \mathrm{~cm}^{-1}$, so we ruled out $\mathrm{CO}$ adsorption. The signal at
$1736 \mathrm{~cm}^{-1}$ concerns $\mathrm{C}=\mathrm{O}$ stretching in carboxylic acids, aldehydes, and ketones. The band at $1447 \mathrm{~cm}^{-1}$ is associated with $\mathrm{O}-$ $\mathrm{C}-\mathrm{O}$ bending in glycolates, glyoxalates, tartonates, and formates, which underlie the production of glycolic, glyoxylic, tartronic, and formic acids, respectively. The peak at $1351 \mathrm{~cm}^{-1}$ is due to $\mathrm{C}-\mathrm{H}$ rotation in aliphatic aldehydes, like glyceraldehyde. The same peak can also be assigned to $\mathrm{COO}^{-}$in formate. Such finding suggests that formic acid production is the most probable $\mathrm{CO}_{2}$ source. Together, these remarks indicate that glycerate arises at potentials as low as $0.2 \mathrm{~V}$, since carboxylate appears as a band at $1447 \mathrm{~cm}^{-1}$. Conversion of glyceraldehyde to glycerate (which absorbs at $2943 \mathrm{~cm}^{-1}$ ) probably occurs from $0.2 \mathrm{~V}$. At $0.4 \mathrm{~V}$, glycerate is converted to glyceric acid. Formate, detected as a band at $1370 \mathrm{~cm}^{-1}$ from $0.4 \mathrm{~V}$, is a probable $\mathrm{CO}_{2}$ source.

The insert in Fig. 6 shows the relative amount of the main compounds originating from glycerol electrooxidation as a function of the electrode potential. Therefore, we propose that carboxylic acid is the main route through which glycerol oxidation starts at $0.4 \mathrm{~V}$. In acidic medium, glycerol electrooxidation at the $\mathrm{PtSb} / \mathrm{C}$ anode involves a very complex mechanism that includes maintenance of the carbon chain up to potentials as high as $0.6 \mathrm{~V}$. $\mathrm{CO}_{2}$ arises after this potential, as a product of previous carboxylic acid electrooxidation.
Table 2 EIRRS absorption assignments of the IR peaks obtained during glycerol electrooxidation at the nanostructured $\mathrm{PtSb} / \mathrm{C}$ anode in acidic and alkaline solutions

\begin{tabular}{|c|c|c|c|}
\hline \multicolumn{2}{|c|}{ Absorption frequency $\left(\mathrm{cm}^{-1}\right)$} & \multirow[t]{2}{*}{ Assignment } & \multirow[t]{2}{*}{ References } \\
\hline $\mathrm{HCIO}_{4}$ & $\mathrm{NaOH}$ & & \\
\hline \multicolumn{2}{|l|}{2943,2886} & $\mathrm{v}_{\mathrm{s}}$ e $\mathrm{v}_{\mathrm{a}}(\mathrm{C}-\mathrm{H})$ of $\mathrm{CH}_{2}$ & {$[27]$} \\
\hline \multicolumn{2}{|l|}{2342} & $\mathrm{v}_{\mathrm{a}}(\mathrm{C}=\mathrm{O})$ of $\mathrm{CO}_{2}$ & {$[28]$} \\
\hline \multirow[t]{2}{*}{1736} & & $\mathrm{v}(\mathrm{C}=\mathrm{O})$ of carboxylic acids, aldehydes, and ketones & {$[27]$} \\
\hline & 1642 & $\delta(\mathrm{H}-\mathrm{O}-\mathrm{H})$ of $\mathrm{H}_{2} \mathrm{O}$ & {$[27]$} \\
\hline \multirow[t]{3}{*}{1626} & & $\mathrm{v}_{\mathrm{s}}(\mathrm{OH})$ of $\mathrm{H}_{2} \mathrm{O}_{\mathrm{ad}}$ & [29] \\
\hline & 1587 & $\mathrm{v}_{\mathrm{a}}(\mathrm{COO}-)$ of formate, glycolate, and glyoxalate ions & {$[30]$} \\
\hline & & $\mathrm{v}_{\mathrm{a}}(\mathrm{C}-\mathrm{O})$ of glyoxal & {$[31]$} \\
\hline \multirow[t]{4}{*}{1447} & & $\mathrm{v}_{\mathrm{s}}(\mathrm{O}-\mathrm{C}-\mathrm{O})$ of carboxylate ions & {$[27]$} \\
\hline & 1390 & $\mathrm{CO}_{3}^{2-}$ & {$[30]$} \\
\hline & 1385 & vs(COO-) of glycerate ions & {$[2]$} \\
\hline & & $\mathrm{v}_{\mathrm{s}}\left(\mathrm{COO}^{-}\right)$of formate ions & {$[30]$} \\
\hline \multirow[t]{3}{*}{1351} & 1351 & $(\mathrm{C}-\mathrm{H})$ of aldehydes in-plane rocking vibration & {$[27]$} \\
\hline & & $\mathrm{v}_{\mathrm{s}}(\mathrm{COO}-)$ of formate ions & {$[30]$} \\
\hline & & $\mathrm{v}_{\mathrm{s}}(\mathrm{COO})$ of hydroxypyruvate ions & {$[2,32]$} \\
\hline \multirow[t]{3}{*}{1263} & & $\mathrm{v}(\mathrm{C}-\mathrm{O})$ of carboxylic acid dimer & {$[27]$} \\
\hline & 1235 & $\mathrm{v}_{\mathrm{s}}(\mathrm{C}-\mathrm{O})$ of carboxylic acid dimer & {$[27]$} \\
\hline & & $\mathrm{v}(\mathrm{C}-\mathrm{O})$ of glycolate ions & {$[33]$} \\
\hline \multicolumn{2}{|l|}{1225} & $\mathrm{v}(\mathrm{C}-\mathrm{O})$ of carboxylic acid dimer & {$[27]$} \\
\hline \multirow[t]{5}{*}{1137} & & $\mathrm{v}(\mathrm{C}-\mathrm{O})$ of alcohol & {$[4]$} \\
\hline & & $\mathrm{v}(\mathrm{Cl}-\mathrm{O})$ of perchlorate ion & {$[27]$} \\
\hline & 1108 & Glycolaldehyde others vibration modes & {$[34]$} \\
\hline & & Glyoxalate others vibration modes & {$[30]$} \\
\hline & 1080 & Glycolate others vibration modes & {$[30-32]$} \\
\hline
\end{tabular}




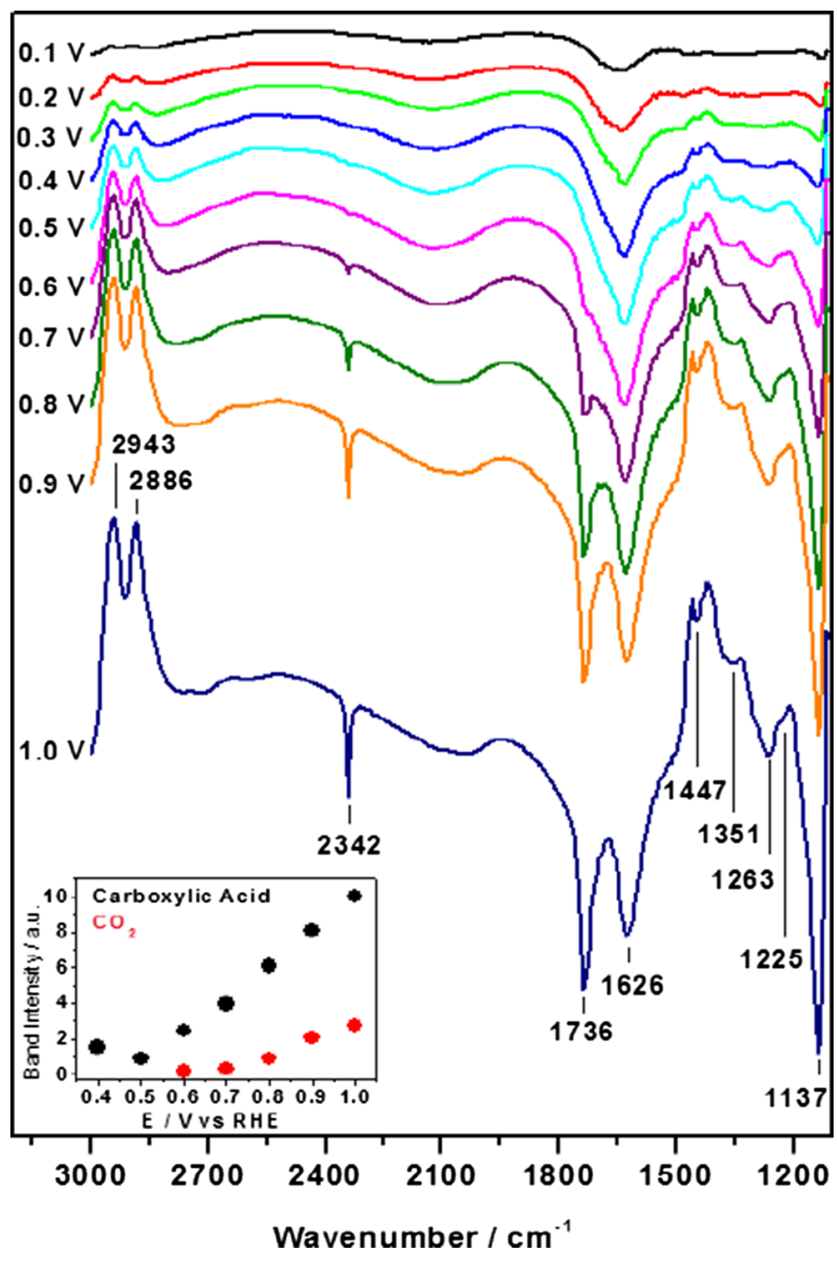

Fig. 6 FTIR spectra of glycerol $\left(0.15 \mathrm{~mol} \mathrm{~L}^{-1}\right)$ electrooxidation at the $\mathrm{PtSb} / \mathrm{C}$ anode, in $\mathrm{HClO}_{4} 0.15 \mathrm{~mol} \mathrm{~L}{ }^{-1} . T=25^{\circ} \mathrm{C} ; 128$ scans; resolution= $8 \mathrm{~cm}^{-1}$. Reference spectrum collected at $0.05 \mathrm{~V}$
Figure 7 suggests pathways for glycerol electrooxidation at the $\mathrm{PtSb} / \mathrm{C}$ anode in acidic medium. This mechanism points out that the electrode material is a poor energy producer, but it can potentially generate interesting chemicals for the industrial sector, for example, glyceraldehyde (a standard for chiral molecules), glyceric acid (useful to treat skin disorders and to serve as an anionic monomer in packaging material for exothermic and volatile agents), glycolic acid (a peeling agent and skin emollient), glyoxylic acid (used in general cosmetic processes), and tartronic acid (a potent adjuvant to increase blood adsorption of a tetracycline antibiotic and to scavenge oxygen in alkaline water) [26].

\section{Alkaline Solution}

Figure 8 contains the EIRRS spectra obtained for glycerol electrooxidation at the $\mathrm{PtSb} / \mathrm{C}$ electrode in $\mathrm{NaOH}$ solution. The band at $1642 \mathrm{~cm}^{-1}$ refers to glyoxal $\mathrm{C}=\mathrm{O}$ stretching or formate $\mathrm{O}-\mathrm{C}-\mathrm{O}$ stretching. The peak at $1587 \mathrm{~cm}^{-1}$ corresponds to glyoxal, formate, or glyoxalate $\mathrm{COO}^{-}$or $\mathrm{C}-\mathrm{O}$ stretching. The absorption at $1390 \mathrm{~cm}^{-1}$ is assigned to carbonate; however, it is possibly affected by the absorptions in the $1460-1370 \mathrm{~cm}^{-1}$ region, associated with glycolate and glycerate. The peak at $1385 \mathrm{~cm}^{-1}$ refers to glycerate or formate $\mathrm{COO}^{-}$stretching. Formate can also absorb at $1351 \mathrm{~cm}^{-1}$. The band at $1235 \mathrm{~cm}^{-1}$ is possibly due to carboxylic acid C-O symmetric stretching, like C-O in glycolate, but oxalic acid C$\mathrm{OH}$ stretching absorbs in the same frequency. In other words, the band at $1235 \mathrm{~cm}^{-1}$ might be due to the glyceric acid that was earlier suggested to underlie the absorption at $1385 \mathrm{~cm}^{-1}$. The peak at $1108 \mathrm{~cm}^{-1}$ is attributed to glycolaldehyde or glyoxalate, which may also account for the absorption at $1080 \mathrm{~cm}^{-1}$. The absorption at $1040 \mathrm{~cm}^{-1}$ corresponds to
Fig. 7 Reaction mechanism proposed for glycerol electrooxidation at the $\mathrm{PtSb} / \mathrm{C}$ anode in acidic medium. (Dashed lines indicate non-detected species)

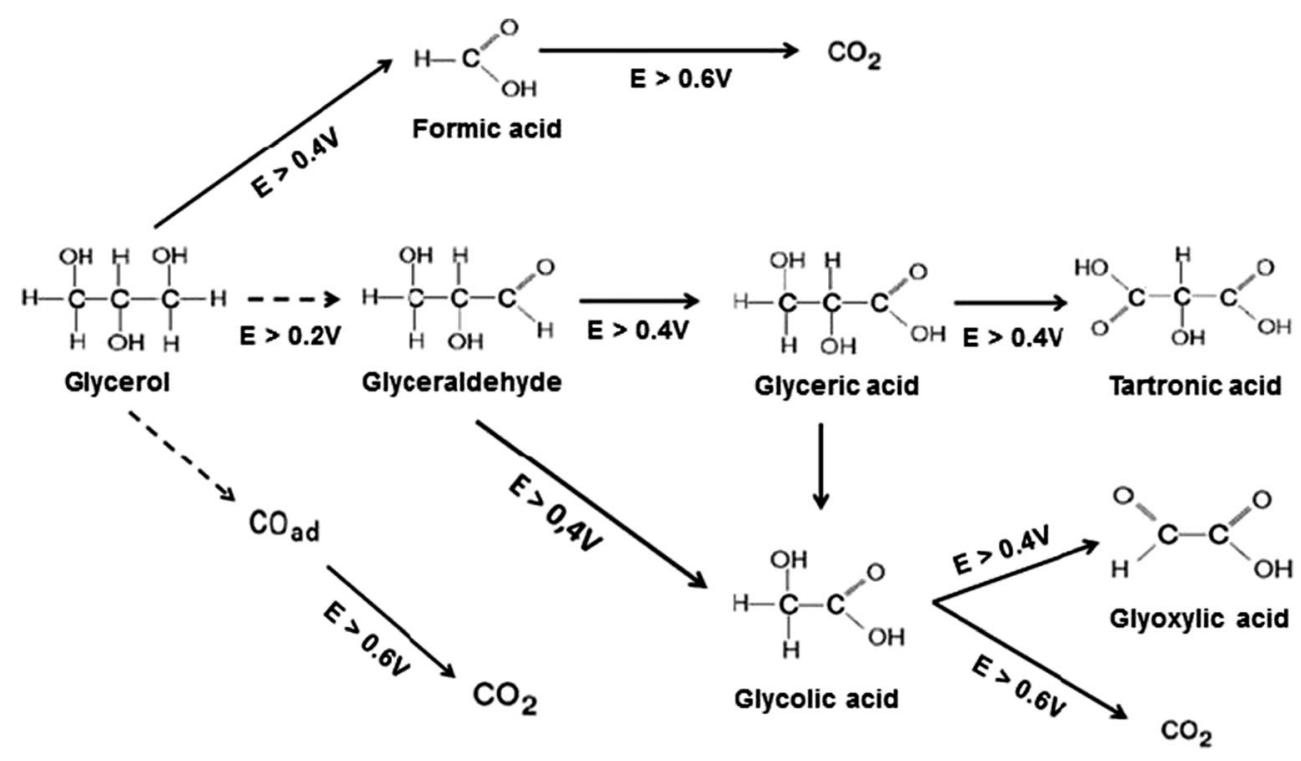


Fig. 8 FTIR spectra of glycerol $\left(0.15 \mathrm{~mol} \mathrm{~L}^{-1}\right)$ electrooxidation at the $\mathrm{PtSb} / \mathrm{C}$ anode, in $\mathrm{NaOH}$ $0.15 \mathrm{~mol} \mathrm{~L}^{-1}$. $T=25^{\circ} \mathrm{C} ; 128$ scans; resolution $=8 \mathrm{~cm}^{-1}$.

Reference spectrum collected at $0.05 \mathrm{~V}$

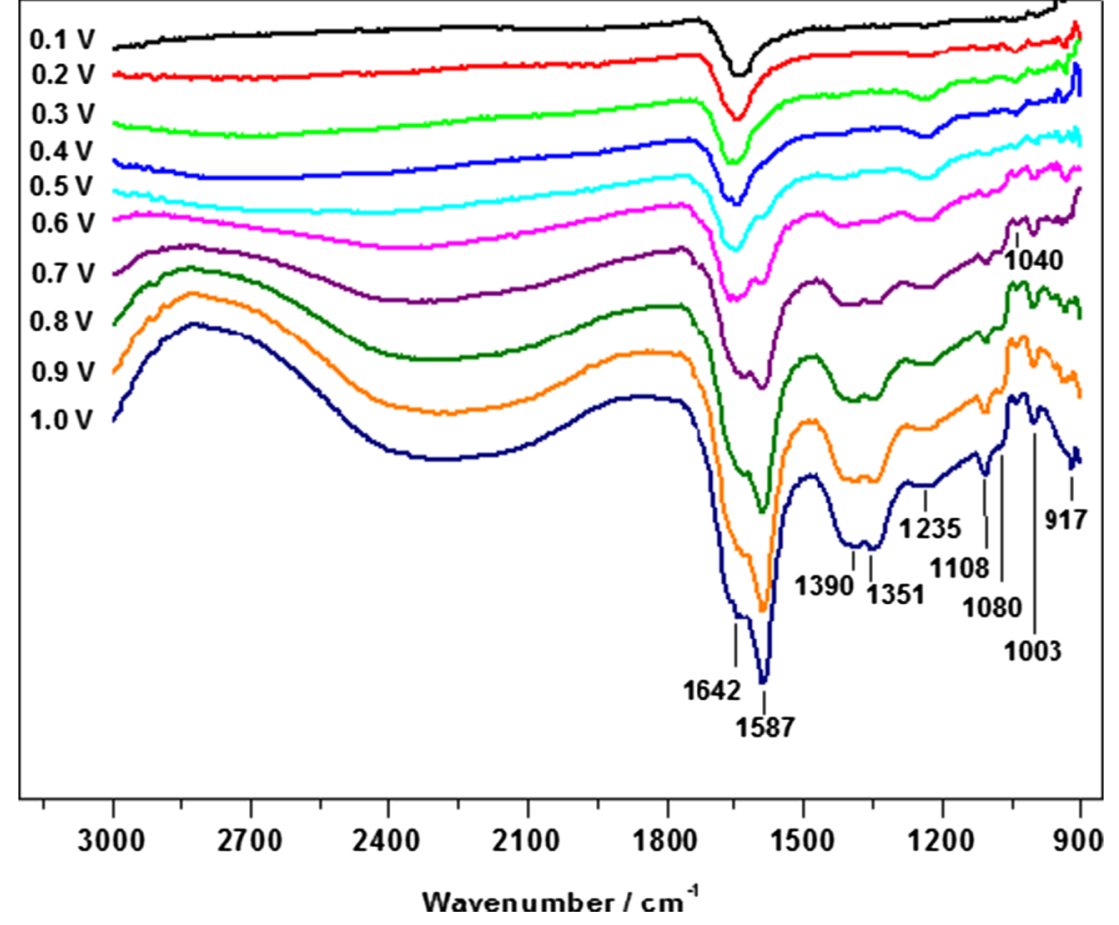

glycolaldehyde or C-O in glycerol. We did not detect any IR absorptions related to $\mathrm{CO}_{2}$ or $\mathrm{CO}_{\text {ads }}$.

Our findings indicate that carboxylic acid and/or glycolate $\left(1235 \mathrm{~cm}^{-1}\right)$ production starts at potentials as low as $0.2 \mathrm{~V}$, which in turn suggests that the glycerol $\mathrm{C}-\mathrm{C}$ bonds cleave due to dissociative adsorption of the glycerol molecule onto the surface of the ordered intermetallic PtSb. The main reason for the low efficiency of the electrooxidation of alcohols with more than two carbon atoms is the difficulty in cleaving the C-C bonds. At $0.2 \mathrm{~V}$, it is still possible to observe IR absorption due to glycolaldehyde and glycerol molecules, which attests that non-cleaved glycerol molecules remain in the solution. This absorption becomes positive at $0.6 \mathrm{~V}$, which points to glycerol consumption in the electrode thin layer. Glycolate and glyoxalate formation clearly takes place from $0.4 \mathrm{~V}$. At $0.5 \mathrm{~V}$, the IR absorption band $\left(1580 \mathrm{~cm}^{-1}\right)$ assigned to glyoxal, formate, glycolate, and glyoxalate arises. Also, at $0.5 \mathrm{~V}$, the band $\left(1400 \mathrm{~cm}^{-1}\right)$ ascribed to glycolate, glycerate, and carbonate appears. At $0.6 \mathrm{~V}$, glycolate emerges as a band at $1080 \mathrm{~cm}^{-1}$. Unfortunately, bands overlap, which makes plotting of the relative amounts of the main products versus the electrode potential unreliable. A possible isomerization reaction between glyceraldehyde and dihydroxyacetone could also occur in alkaline medium. On the basis of the results,
Fig. 9 Reaction mechanism proposed for glycerol electrooxidation at the $\mathrm{PtSb} / \mathrm{C}$ anode in alkaline medium

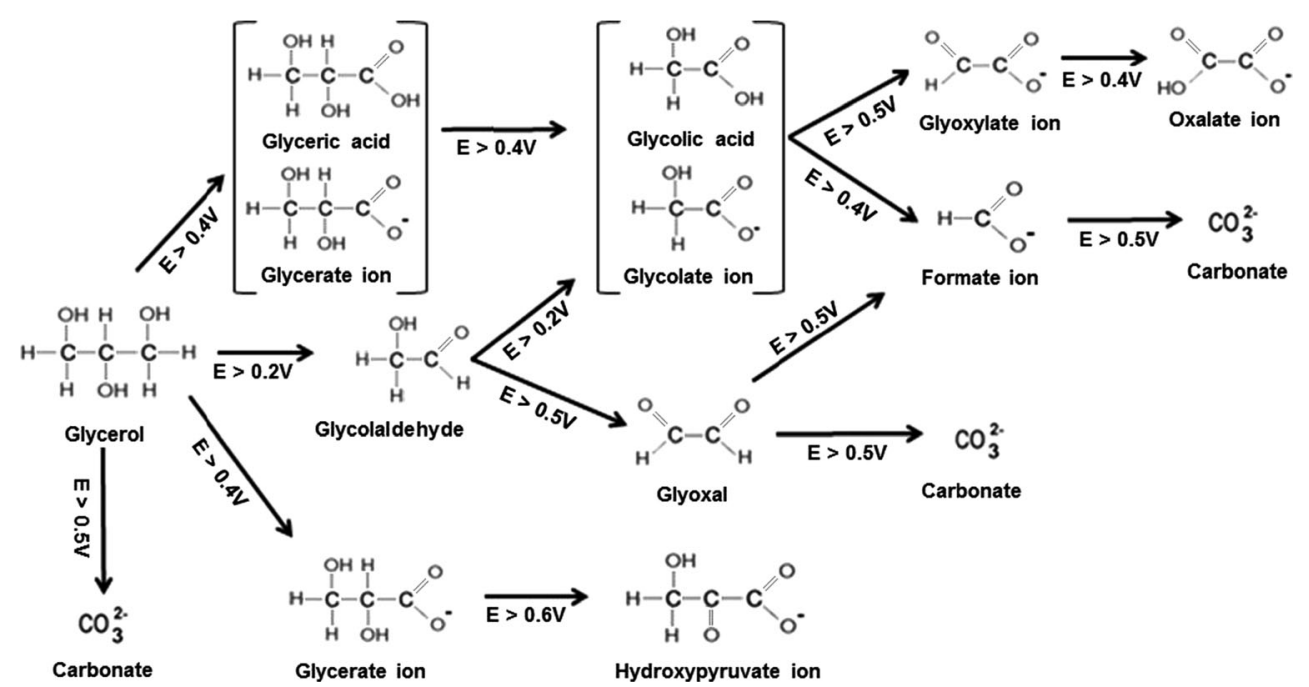


Fig. 9 depicts the proposed mechanism for glycerol electrooxidation in alkaline medium.

It is noteworthy that $\mathrm{PtSb}$ promotes dissociative adsorption of glycerol molecules with C-C bond cleavage in the hydrogen region. Some glycerol molecules remain intact for participation in further electrochemical steps. The main route for glycerol electrooxidation at the $\mathrm{PtSb} / \mathrm{C}$ anode in alkaline medium is carbonate or oxalate production via the glyoxal pathway. The electron-donating action of $\mathrm{Sb}$ atoms improves the adsorptive features of the Pt surface site, especially in the particular structural configuration of the ordered intermetallic $\mathrm{PtSb}$ nanoparticle. This must be the cause for the outstanding performance of nanostructured $\mathrm{PtSb} / \mathrm{C}$ in glycerol electrooxidation in alkaline medium.

\section{Conclusion}

A modified polyol route afforded ordered intermetallic nanostructured PtSb (1:1) supported on carbon. In acidic medium, the $\mathrm{PtSb} / \mathrm{C}$ material served as anode for glycerol electrooxidation, to give yields as high as those achieved with commercially available Pt (E-TEK) nanoparticles under the same experimental conditions. In alkaline solution, the material performed almost $50 \%$ better than Pt. Such a performance was due to the role played by $\mathrm{Sb}$ atoms, which improved the Pt surface and activated C-C bond cleavage in glycerol. Spectroelectrochemical studies in acidic medium confirmed that glycerol electrooxidation at the $\mathrm{PtSb} / \mathrm{C}$ anode produced several chemical species with useful applications in the industrial field. In alkaline solution, the reaction at the $\mathrm{PtSb} / \mathrm{C}$ anode presented outstanding electrochemical efficiency. In conclusion, we have demonstrated the potential ability of ordered intermetallic $\mathrm{PtSb} / \mathrm{C}$ to serve as a source of chemical or electrical energy via glycerol electrooxidation.

Acknowledgments Authors thank Fundaçao de Amparo à Pesquisa do Estado de Sao Paulo (FAPESP) for financial support (process \# 2013/05634-8), and T.P. Scachetti thanks Conselho Nacional de Desenvolvimento Científico e Tecnológico $(\mathrm{CNPq})$ for the graduate fellowship.

\section{References}

1. C.W. Xu, Z.Q. Tian, P.K. Shen, S.P. Jiang, Electrochim. Acta 53, $2610(2008)$

2. M. Simões, S. Baranton, C. Coutanceau, Appl. Catal. B Environ. 93, 354 (2010)
3. Y. Kwon, M.T.M. Koper, Anal. Chem. 82, 5420 (2010)

4. J.F. Gomes, G. Tremiliosi-Filho, Electrocatalysis 2, 96 (2011)

5. M. Simões, S. Baranton, C. Coutanceau, Appl. Catal. B Environ. 110, 40 (2011)

6. S.W. Xie, S. Chen, Z.Q. Liu, C.W. Xu, Int. J. Electrochem. Sci. 6, $882(2011)$

7. P.S. Fernández, M.E. Martins, G.A. Camara, Electrochim. Acta 66, $180(2012)$

8. E. Habibi, H. Razmi, Int J. Hydrog. Energy 37, 16800 (2012)

9. Z. Zhang, L. Xin, W. Li, Int J. Hydrog. Energy 37, 9393 (2012)

10. P.S. Fernández, C.A. Martins, M.E. Martins, G.A. Camara, Electrochim. Acta 112, 686 (2013)

11. J.H. Zhang, Y.J. Liang, N. Li, Z.Y. Li, C.W. Xu, S.P. Jiang, Electrochim. Acta 59, 156 (2012)

12. H.J. Kim, S.M. Choi, S. Green, G.A. Tompsett, S. HwaLee, G.W. Huber, W.B. Kim, Appl. Catal. B Environ. 101, 366 (2011)

13. A. Falase, M. Main, K. Garcia, A. Serov, C. Lau, P. Atanassov, Electrochim. Acta 66, 295 (2012)

14. A. Zalineeva, M. Padilla, U. Martinez, A. Serov, K. Artyushkova, S. Baranton, C. Coutanceau, P.B. Atanassov, J. Am. Chem. Soc. 136, 3937 (2014)

15. E. Casado-Rivera, D.J. Volpe, L. Alden, C. Lind, C. Downie, T. Vázquez-Alvarez, A.C.D. Angelo, F.J. DiSalvo, H.D. Abruña, J. Am. Chem. Soc. 126, 4043 (2004)

16. C. Roychowdhury, F. Matsumoto, V.B. Zeldovich, S.C. Warren, P.F. Mutolo, M.J. Ballesteros, U. Wiesner, H.D. Abruña, F.J. DiSalvo, Chem. Mater. 18, 3365 (2006)

17. M.R. Silva, A.C.D. Angelo, Electrocatalysis 1, 95 (2010)

18. Y. Feng, W. Yin, Z. Li, C. Huang, Y. Wang, Electrochim. Acta 55, 6991 (2010)

19. Y. Feng, Z. Li, C. Huang, Y. Wang, Ionics 17, 617 (2011)

20. N. Perini, B.C. Batista, A.C.D. Angelo, I.R. Epstein, H. Varela, ChemPhysChem 15, 1753 (2014)

21. N. Perini, E. Sitta, A.C.D. Angelo, H. Varela, Catal. Commun. 30, 23 (2013)

22. R.E. Cable, R.E. Schaak, Chem. Mater. 17, 6835 (2005)

23. P.S. White, J.R. Rodgers, Y.L. Page, Acta Crystallogr. B 58, 343 (2002)

24. P.S. Fernández, M.E. Martins, C.A. Martins, G.A. Camara, Electrochem. Commun. 15, 14 (2012)

25. B. Peng, H.F. Wang, Z.P. Liu, W.B. Cai, J. Phys. Chem. C 114, $3102(2010)$

26. A. Behr, J. Eilting, K. Irawadi, J. Leschinski, F. Lindner, Green Chem. 10, 13 (2008)

27. G. Sócrates, Infrared Characteristic Group Frequencies: Tables and Charts, 2nd edn. (Wiley, New York, 1994), p. 347

28. S.G. Sun, in Electrocatalysis: Frontiers in Electrochemistry, ed. by J. Lipkowski, P.N. Ross (Wiley-VCH, New York, 1998), p. 279

29. B. Beden, C. Lamy, N.R. de Tacconi, A.J. Arvia, Electrochim. Acta 35, 691 (1990)

30. S.-C. Chang, Y. Ho, M.J. Weaver, J. Am. Chem. Soc. 113, 9506 (1991)

31. P.A. Christensen, A. Hamnett, J. Electroanal. Chem. 260, 347 (1989)

32. D.Z. Jeffery, G.A. Camara, Electrochem. Commun. 12, 1129 (2010)

33. L. Demarconnay, S. Brimaud, C. Coutanceau, J.-M. Léger, J. Electroanal. Chem. 601, 169 (2007)

34. L.-W.H. Leung, M.J. Weaver, Langmuir 6, 323 (1990) 